Benjamin D. Thomas

\title{
Hezekiah and the Compositional History of the Book of Kings
}

[Hiskia und die Kompositionsgeschichte der Königsbücher.]

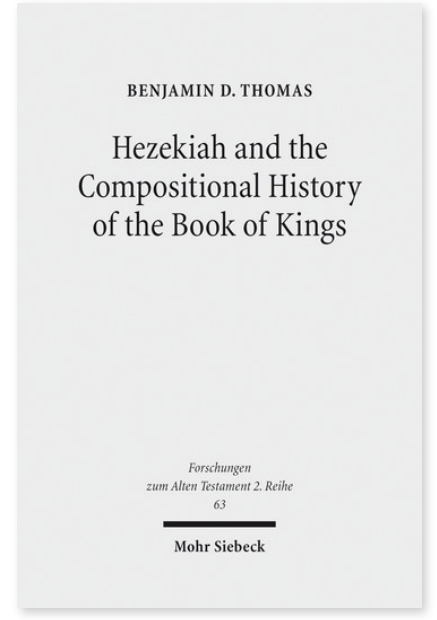

2014. XIX, 508 Seiten. FAT II 63

ISBN 978-3-16-152955-9

DOI 10.1628/978-3-16-152955-9

eBook PDF $129,00 €$

ISBN 978-3-16-152935-1

fadengeheftete Broschur 129,00€
Veröffentlicht auf Englisch.

Benjamin D. Thomas untersucht in dieser Studie eines der ältesten und zentralsten Probleme der hebräischen Bibel - die Kompositionsgeschichte des 1. und 2. Buchs der Könige. Er geht jedoch nicht von der Annahme aus, die seit de Wette vorherrscht, nämlich, dass der Ursprung von 1 und 2 Kön innerhalb einer deuteronomischen literarischen Redaktion gesehen werden kann, die in der josianischen Reform wurzelte. Stattdessen liest der Autor 1 und 2 Kön im historischen Kontext anderer Texte aus ähnlichen Genres. Er versucht zudem den Umfand der ursprünglichen Struktur zu ermitteln, indem er den Anfang und den Schluss entschlüsselt. Thomas' Ergebnisse zeigen, dass der ursprüngliche Text mit der Salomo-Erzählung beginnt und seine Klimax in der Hiskia-Erzählung hat, die letzteren als königlichen YHWHisten par excellence darstellt, der die Ordnung wieder herstellt und den Ort für Opfergaben auf Jerusalem beschränkt.

Benjamin D. Thomas Born 1980; PhD in Hebrew Bible and the Ancient Near East from the University of Chicago; currently a Research Project Professional at the Oriental Institute in Chicago.
Jetzt bestellen:

https://mohrsiebeck.com/buch/hezekiah-and-the-compositional-history-of-the-book-of-kings-9783161529559?no_cache=1 order@mohrsiebeck.com

Telefon: $+49(0) 7071-923-17$

Telefax: $+49(0) 7071-51104$ 